\title{
Crisis intervention and acute psychiatry in Amsterdam: 20 years of change? A historical comparison of consultations in 1983 and 2004 - 2005
}

\author{
Jack Dekker*, Louk van der Post, Irene Visch and Robert Schoevers
}

Address: Mentrum Mental Health Institute, Klaprozenweg 111, 1070 AV Amsterdam, Netherlands

* Corresponding author

from WPA Thematic Conference. Coercive Treatment in Psychiatry: A Comprehensive Review

Dresden, Germany. 6-8 June 2007

Published: 19 December 2007

BMC Psychiatry 2007, 7(SuppI I):SI49 doi:I0.II86/I47I-244X-7-SI-SI49

This abstract is available from: http://www.biomedcentral.com/I47I-244X/7/SI/SI49

(c) 2007 Dekker et al; licensee BioMed Central Ltd.

\section{Background}

To establish a picture of the changes in emergency psychiatry that have contributed to the sharp increase in the number of acute compulsory admissions in the Netherlands since 1992. Treatment in Amsterdam psychiatric clinics is in danger of being dominated by coercive treatment. These developments imply that patients with severe mental illnesses more often progress to stages in which acute, coercive treatment is warranted. It is clear that this is an unsolicited trend, which not only leads to a reduction of patient autonomy but also has a negative effect on the prognosis of these disorders.

\section{Methods}

A cohort $(\mathrm{N}=460)$ of psychiatric emergency consultations by the city crisis service in 1983 was compared with a similar cohort $(\mathrm{N}=436)$ in $2004-2005$, looking at the following variables: patient characteristics, crisis-service procedures and consultation outcomes.

\section{Results}

In comparison with 1983, more services are currently involved with psychiatric patients in acute situations in the public domain. The percentage of patients that were referred by the police has doubled. In 1983, all consultations took place where the patients were located; at present, $60 \%$ take place at the crisis service premises. The number of psychotic patients in the cohort has increased from 52 to $63 \%$. There has been an increase of compulsory admissions and a sharp decrease of voluntary admis- sions (from $25.7 \%$ to $7.6 \%$ ). Overall, the percentage of consultations leading to a psychiatric admission has decreased from $42 \%$ to $27 \%$.

\section{Conclusion}

The front-line outreach service of 1983 has changed into a specialist psychiatric emergency department with a less pronounced outreach component. Voluntary admissions in a psychiatric hospital have almost disappeared as a feature of the crisis service. Further research is required into the characteristics of the consultations and into the variables that play a role in the use of compulsion in emergency psychiatry. 